\title{
A Study on Access Control Technology for a Multimedia

\author{
Based E-Learning System : A Learning Intervention
}

\author{
Tai-hoon Kim¹)
}

\begin{abstract}
Education is essential, so students should understand the topic in their native language. If a textbook is used that is insufficient for a teacher's education, students lose interest. In the course of the training, it is natural to monitor students' progress in learning. Some teachers may not be effective in teaching a subject, in which case students lack understanding of the subject. The teacher offers proofreading classes for students who have difficulty understanding the subject. The purpose of this study is to introduce access control concepts while participating in interactive learning processes and reviewing multimedia-based e-learning systems as a tool for interacting learners.
\end{abstract}

Keywords : E-Learning, Multimedia, Security, Assurance, Access Control

\section{Introduction}

Two essential elements for effective learning are to set goals and motivate students to actively participate in the learning process. Therefore, teachers should provide effective teaching strategies that students need to learn subjects easily. Motivation for learning stimulates the interest of participating students and encourages active participation in the learning process. Generally, there are teachers who use teaching methods effectively, and there are teachers who are not able to perform their teaching activities properly.

For a variety of reasons, including these, teachers should design a teaching learning strategy[1]. There are many reasons why teachers fail to establish learning strategies. There are many factors affecting students' ability to learn, such as the distracting environment, family problems, personal interests, and student diversity. When these factors are applied in various ways, students have a hard time learning subjects. Slow learners tend to lag behind fast learners in understanding subjects. In such cases, supplementary classes may be conducted.

Received(September 20, 2017), Review Result(1st: October 17, 2017, 2nd: November 20, 2017), Accepted(December 10, 2017)

1) Dept. of Convergence Security, Sungshin W. University 2, Bomun-ro 34da-gil, Seongbuk-gu, Seoul, Korea taihoonn@sunghin.ac.kr 
To solve the above problems, various research institutes developed effective teaching methodologies to help students learn and developed tools to implement them. With the advent of information and communication technologies, advanced forms of educational tools have been created by educational experts. Recent and popular tools incorporate multimedia presentations and ICTs, which allow modern educational tools to replace so-called traditional educational tools[2].

Multimedia learning methods can provide students with a completely different type of learning experience and provide new directions to progress. Multimedia is a good tool to help students learn, and by enabling classes using sight and hearing, students are given a high level of motivation.

With the advancement of information and communication technology, students have had the opportunity to perform their learning activities more effectively. Multimedia learning has affected the overall improvement of the education system, which has led to the development of education. Multimedia education consists of e-learning, and is one form of CAI (Computer Support Training).

Through multimedia-based learning using computers and the Internet, students can proceed with a variety of studies. However, because the process of students' learning using multimedia is very disruptive, it is recommended that teachers conduct supervision in order to promote their learning.

When a class is conducted in a multimedia format, it can stimulate students' interest and help them increase their understanding of the class. The combined operation of interactive e-learning systems and field classes is beneficial for both students and teachers. In particular, these systems can be developed as mobile applications and can be used everywhere[3].

\section{Background of the Study}

\subsection{Meaning of Multimedia}

The introduction of multimedia has led to rapid development of learning theory and tools. Multimedia is content created by combining various elements, such as text, animation, audio, and images. Therefore, multimedia is different from the traditional form of learning media, either printed or handmade[4]. 


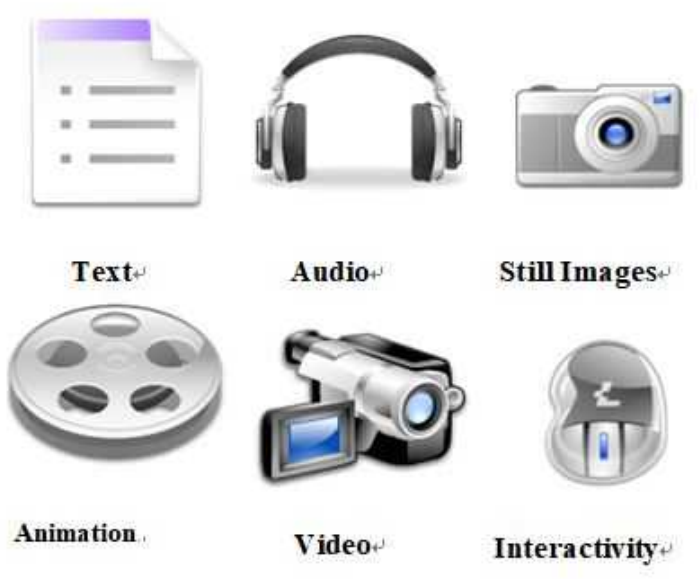

[Fig. 1] Components of Multimedia

Multimedia can be recorded and played using information processing devices such as computers. It also enables interaction between multimedia providers and receivers. Multimedia devices are similar to general information processing devices, but they are media devices that are specialized for storing and playing multimedia content.

\subsection{Multimedia System}

Multimedia used in education is used to develop computer-based training courses and to produce relevant references. Using CBT, professors can provide a variety of learning materials on a particular topic, and can also manage the materials associated with game or other contents.

\subsection{Photoshop and Flash}

Photoshop supports a wide range of graphics file formats. And it provides simple functions to render text, graphics and videos. It used to have the highest efficiency and market share in the industry until recently, but has been struggling with the development and release of various tools. Because it has limited functionality compared to illustrators, it is still a good tool for doing simple tasks, although experts are often assessed to be impetuous to use. [5][6].

Flash has been a popular multimedia production tool until recently. Unfortunately, Adobe plans to terminate its support for this platform by 2020[7]. As international standards shift to HTML5, most technologies are supported without Flash[8]. 


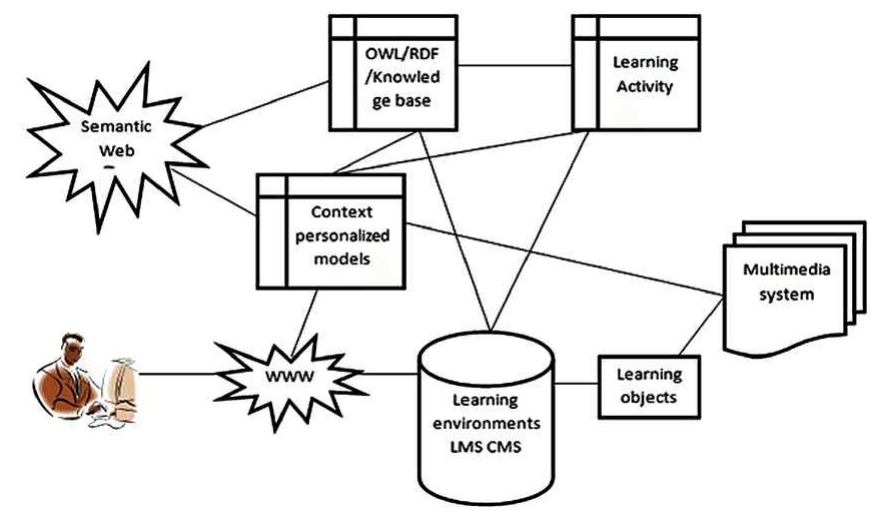

[Fig. 2] Basic E-learning Framework using Multimedia System

\section{Prototype Model}

This study uses the prototype type creation methodology, which is part of the software development process. The prototype type allows developers to organize the functions they need and make the necessary changes and corrections.

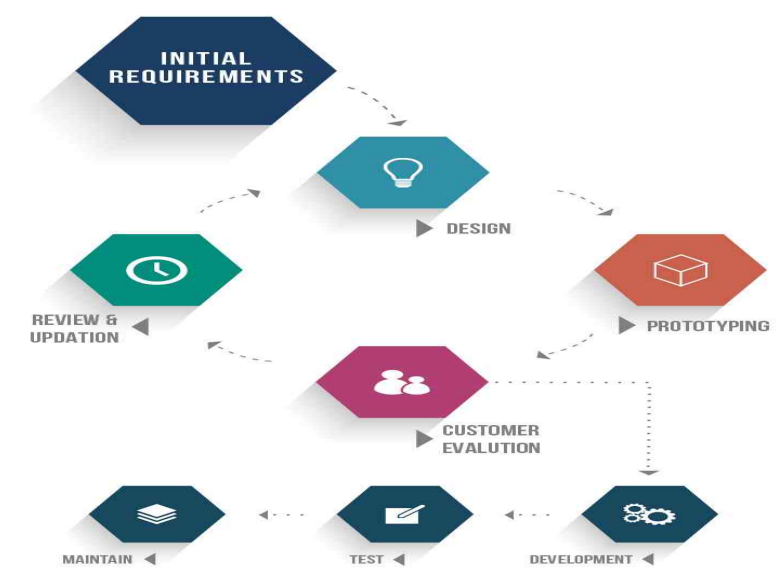

[Fig. 3] Prototype Model

\section{Conceptual Framework}

The objectives of this study are to develop a multimedia system for managing interactive learning processes and to introduce security concepts. 
The configuration of the eLearning system is very simple. First, let learners create an account to $\log$ on to the system. If you are creating an account, make sure that you complete all the conditions available to the e-learning system. The learners should be able to log in and look at the entire course.

The student must go through the procedures for learning, testing, evaluation and review. The first step is to guide you to repeat your multimedia classes anytime, anywhere. Once the learners have finished the class, they will need to take a test on a specific topic to see how much they understand.

Test results are required to check progress. The third step is evaluation. At this stage, not only the learners themselves but also the teachers can see the results. If the results of the survey do not exceed the expected level, review to compensate. At this stage, learners will be able to supplement their knowledge.

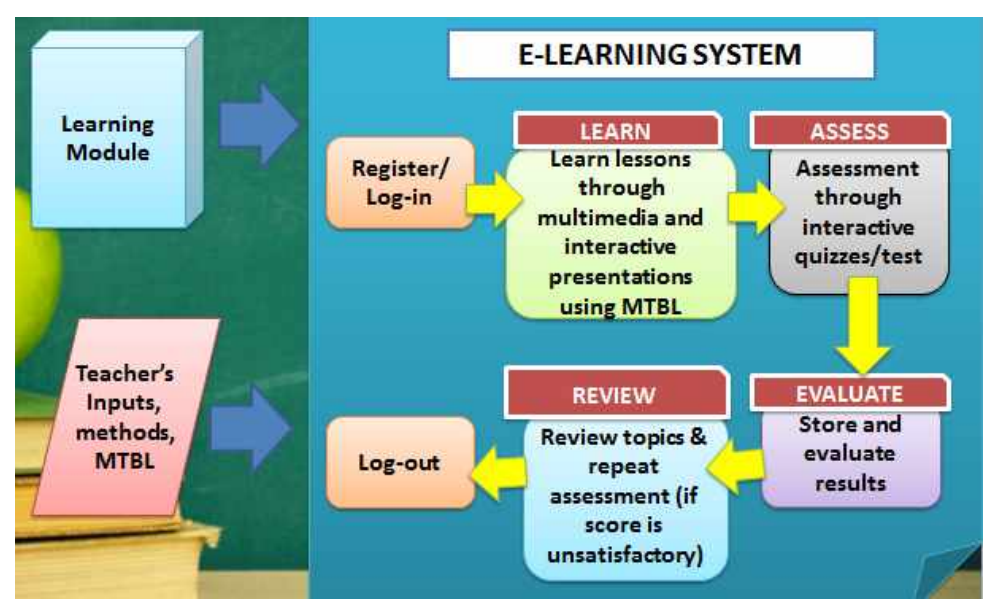

[Fig. 4] Conceptual Framework

\section{Threats to Multimedia}

Next [Fig. 5] is a diagram depicts the concept of threat to Multimedia and Multimedia systems. Multimedia systems are the systems support successful Multimedia interactivities. From now on, when I mention about the Multimedia, please think it contains Multimedia systems.

Most important thing is an our asset, Multimedia. For example, please consider we have very helpful AVI file contains the investment trend of 10 major companies. In this case, someone want to abuse this file with their own, and they will generate threat to our asset and find vulnerabilities to get this file. All these action of someone who can use our asset without 
agreement will increase Risk to our assets. If we are the owner of this file, and if we detect or acknowledge these threats, we may take or buy technical and non-technical methods to protect our file. This is a countermeasure for our assets and this can be a start point of security concept.

Security measures are in place and work well, but problems usually remain. A major problem is the belief that security measures can protect your multimedia from damage.

Typically, once security measures have been established and work has begun, owners and administrators may think that multimedia is safe. This is a very large security hole that is not solved by the physical system. For example, you have purchased and installed IDS, but it is not possible to detect all electronic intrusions.

- Did a malicious developer create IDS?

- What if the back door code was inserted into the IDS?

- Who can predict the results of the IDS installation?

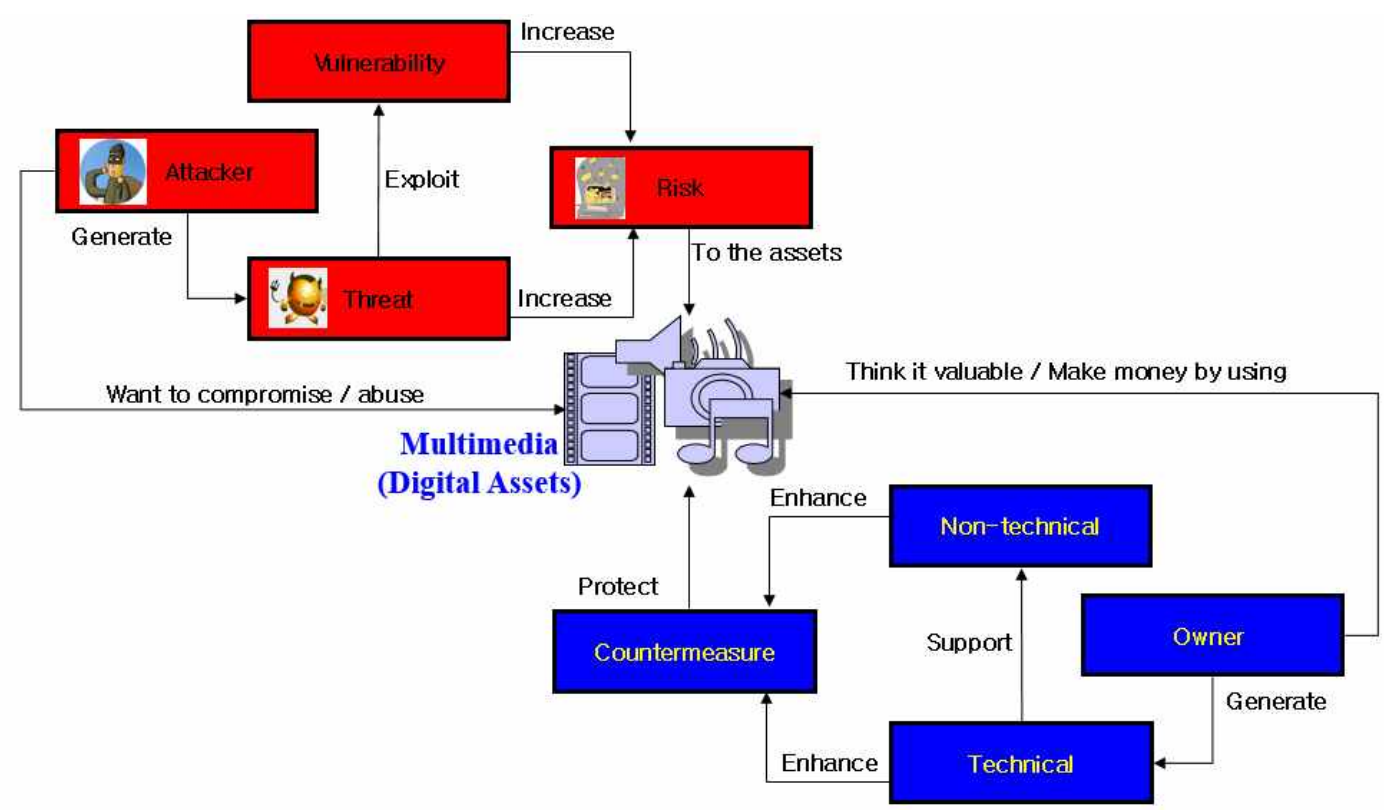

[Fig. 5] Security Concept for Multimedia

Can we trust that the security countermeasures can reduce the RISK effectively and protect Multimedia Assets? 


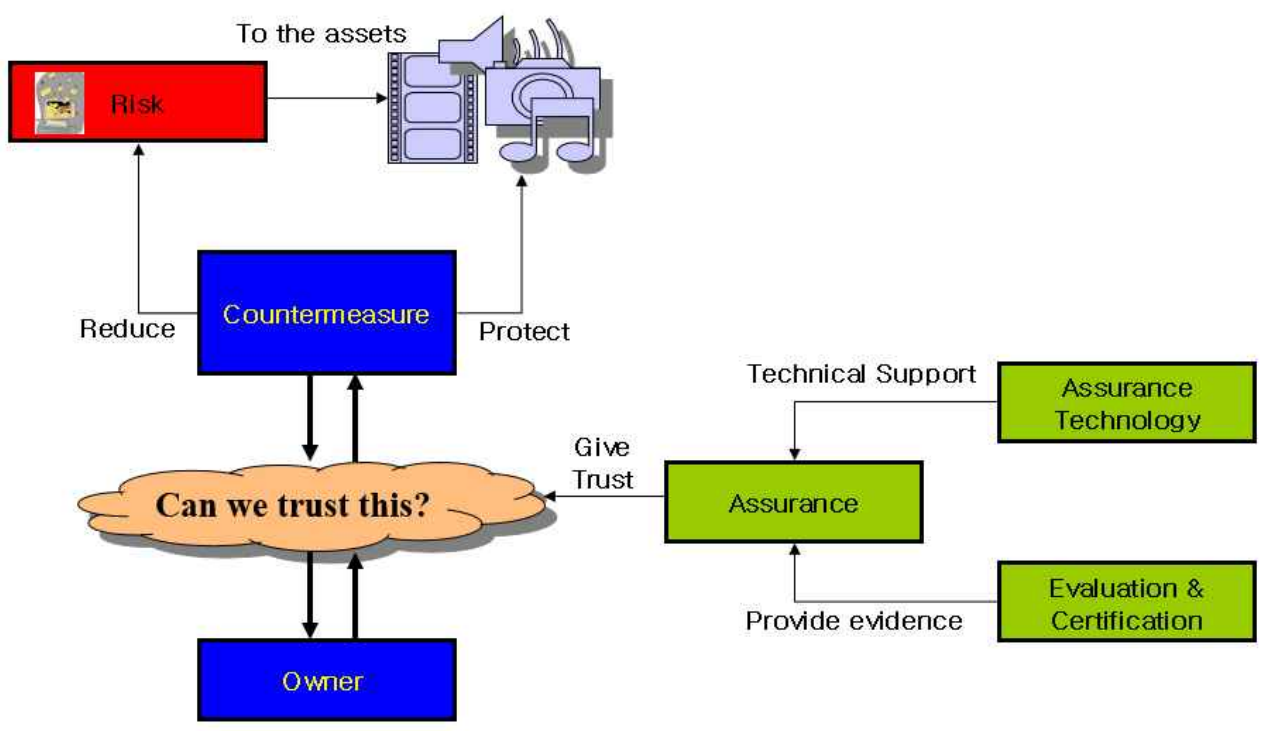

[Fig. 6] Security Countermeasures for Multimedia

Multimedia systems are made up of so many other components and have all kinds of security measures. Next [Fig. 7] describes the relationship between security and assurance to be considered in the following research.

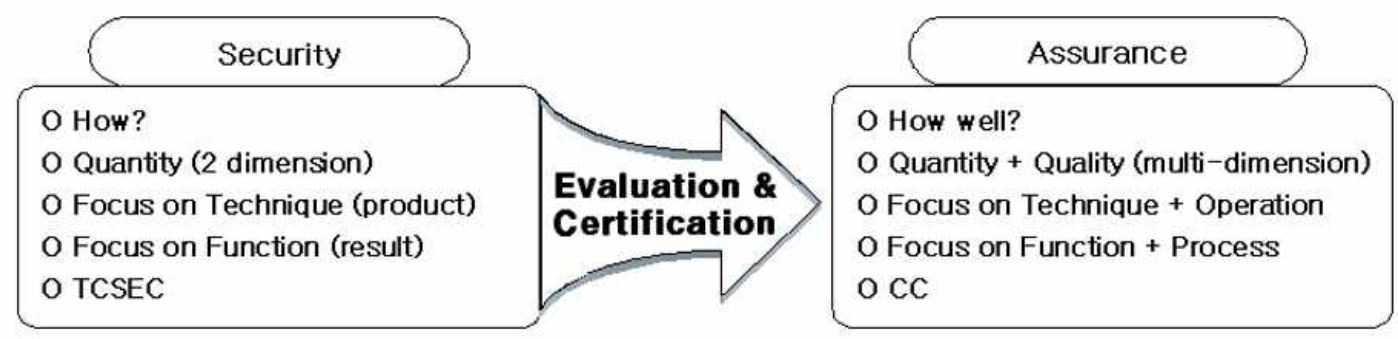

[Fig. 7] Security Assurance for Multimedia

\section{Access Control}

Access control is required to prevent illegal access to shared or important resources. Access control is required to protect the personal information associated with learners using eLearning, including content and services provided through the eLearning support system. So, Elke Franz and others studied how user data and content were protected in a real world of remote learning. The functions required to achieve access control to systems responsible for multimedia-based remote education are provided through the PIM recognition platform through 
PRIME, a project underway in Europe [9].

\section{Conclusion and Future Research}

Based on information and communication technologies, education and learning activities using multimedia can be effectively carried out. Over time, e-learning using multimedia will improve the overall education field.

Another important factor in multimedia learning is security. If the system is vulnerable to security, learners will be able to bypass the system at some point and avoid In this case, the effect of learning is unpredictable. In addition, some users may want to hack into online learning courses that are paid for free or steal content.

Although the study was written at a level that introduces the applicable security concepts for multimedia, the next study will be to develop and apply technical and administrative elements.

\section{Acknowledgement}

This work was supported by the Sungshin University Research Grant of 2017.

\section{References}

[1] Henderson, H., Encyclopedia of Computer Science and Technology Revised Edition, Infobase Publishing, New York, (2009), p.99.

[2] Erica Melis, Markus Weber and Eric Andrès, Lessons for (Pedagogic) Usability of eLearning Systems, E-Learn: World Conference on E-Learning in Corporate, Government, Healthcare, and Higher Education, 2003 in Phoenix, Arizona, USA, ISBN 978-1-880094-50-1, Publisher: Association for the Advancement of Computing in Education (AACE), (2003), pp.281-284, https://www.learntechlib.org/p/14936/.

[3] D. Lassner \& C. McNaught (Eds.), Incorporating interoperability into a distributed eLearning system, In Proceedings of ED-MEDIA 2003-World Conference on Educational Multimedia, Hypermedia \& Telecommunications, Honolulu, Hawaii, USA, Publisher: Association for the Advancement of Computing in Education (AACE), (2003), pp.273-282, https://www.learntechlib.org/p/13759/.

[4] Gallagher, S. Sixmith, A., Engaging IT undergraduates in non-IT content: Adopting an eLearning information system in the classroom, Interactive Technology and Smart Education, (2014), Vol.11, No.2, pp.99-111, https://doi.org/10.1108/ITSE-04-2014-0004 
[5] https://en.wikipedia.org/wiki/Adobe_Photoshop\#CS5, Retrieved 15 September 2017.

[6] https://en.wikipedia.org/wiki/Adobe_Photoshop, Retrieved 15 September 2017.

[7] https://en.wikipedia.org/wiki/Adobe_Flash_Player, Retrieved 15 September 2017.

[8] Warren, Christina, The Life, Death and Rebirth of Adobe Flash, Mashable; http://mashable.com/2012/11/19/history-of-flash/\#KHywJYIDfPqO, Retrieved 20 November 2012.

[9] Elke Franz, Hagen Wahrig, Alexander Böttcher, Katrin Borcea-Pfitzmann, Access control in a privacy-aware eLearning environment, The First International Conference on Availability, Reliability and Security, May (2006), DOI: $10.1109 /$ ARES.2006.20 